\title{
Jornalismo político no Brasil: polarização estéril ou arena de debates?
}

\author{
Political journalism in Brazil: sterile polarization or arena of debates?
}

\author{
Eleonora de Magalhães \\ Doutoranda pelo Programa de Pós-graduação em \\ Comunicação, Universidade Federal Fluminense (UFF), \\ Niterói, RJ, Brasil \\ eleonoramaga@gmail.com
}

Resumo: O artigo propõe discutir a relação entre imprensa e política no Brasil sob uma perspectiva comparativa. O estudo possui como ponto de partido a observância do fortalecimento do jornalismo partidário paralelamente à tensão entre "mídia tradicional" (jornais e revistas de grande circulação) e "novos agentes" (em especial, blogs de jornalismo político), fenômeno atravessado pelo movimento de "virada à esquerda", especialmente na América Latina, que levou ao poder agentes historicamente marginais no cenário político. O objetivo é compreender a cultura do jornalismo brasileiro contemporâneo a partir de um olhar periférico, pensando-a como fenômeno cultural e geograficamente situado, e não como desvio a um "modelo" estabelecido de jornalismo. Para tanto, a discussão contemplará quatro aspectos fundamentais: 1) o desenvolvimento do modelo informativo/liberal de jornalismo comparativamente a outros "sistemas midiáticos"; 2) a relação entre imprensa, mercado e governo; 3) o lugar que jornais e jornalistas propõem ocupar nas sociedades em que atuam; e 4) a relação entre jornalismo e política no Brasil, contemplando o aparecimento de novos agentes possibilitados de entrar em cena com o desenvolvimento da Internet. $\mathrm{O}$ trabalho ainda propõe refletir em torno dos indicativos de uma tensão entre "imprensa tradicional" - representada pelos maiores e principais meios noticiosos brasileiros - e novos agentes políticos - em especial os" blogueiros progressistas" ou "de esquerda".

Palavras-chave: Jornalismo político; Polarização; Blogosfera progressista; Democracia.

\footnotetext{
Abstract: The article intends to discuss the relationship between the press and politics in Brazil from a comparative perspective. The work has as start point the strengthening of partisan journalism in parallel to the tension between "traditional media" (newspapers and general circulation magazines) and "new agents" (especially political journalism blogging), phenomenon permeated by the so called "left turn", especially in Latin America, which led to power historically marginal actors on the political scene. The goal is to understand the culture of contemporary Brazilian journalism from a peripheral perspective, thinking it as a cultural phenomenon and geographically located; not as a deviation from a "model" of journalism already consolidated. Therefore, the discussion will cover four key aspects: 1) the development of the informativel liberal model of journalism compared to other "media systems", 2) the relationship between media, market and government; 3) the
} 
place that newspapers and journalists propose to take in the societies in which they operate; and 4) the relationship between journalism and politics in Brazil, considering the emergence of new agents that became enabled to step in with the development of the Internet. The paper also has the goal to reflect about evidences of a tension between "mainstream media" - represented by the largest and leading Brazilian newspapers - and new political actors - especially the "progressive bloggers" or "left bloggers".

Keywords: Political journalism; Polarization; Progressive blogosphere; Democracy.

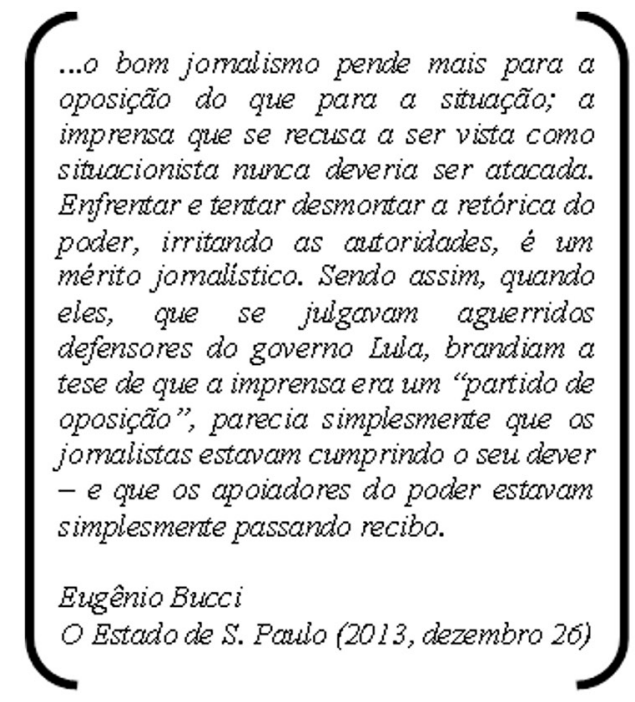

No Brasil, o amadurecimento de uma democracia presidencialista nos últimos trintas anos caminhou lado a lado ao fortalecimento de um partido político, o Partido dos Trabalhadores (PT)1. Isso aponta para um modelo de democracia em que a variável "partidos políticos" ganha proporção na relação entre imprensa e política. Levando isso em consideração, os exemplos acima podem ser compreendidos de duas maneiras: a) como ilustrativos da atual relação entre jornalismo e política no Brasil, apontam para questões ideológicas que permeiam a imprensa do país e envolvem identificações partidárias, tanto à esquerda quanto à direita no espectro político, contempladas por segmentos da imprensa nacional; b) e como indicativos de uma tensão entre "imprensa tradicional", representada pelos maiores e principais meios noticiosos brasileiros (jornais Folha de S. Paulo, O Estado de S. Paulo e O Globo e a

\footnotetext{
${ }^{1}$ Sobre identificação partidária, principalmente no que concerne à força do PT junto ao eleitorado brasileiros, ver Braga e Pimentel Junior (2011), Borba, Carreirão e Ribeiro (2011), Paiva e Tarouco (2011), Veiga (2011).
}

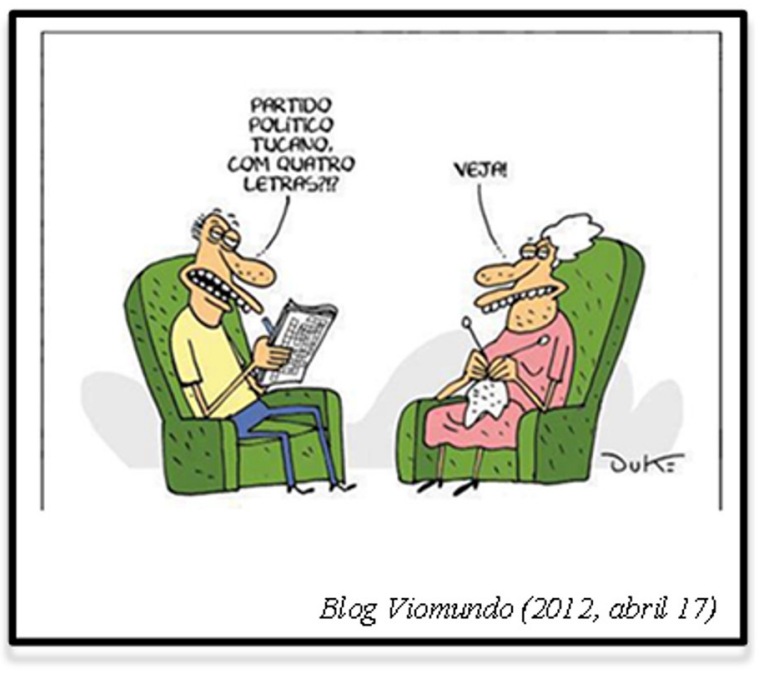

revista Veja), de um lado, e novos agentes políticos, os blogueiros "progressistas" ou "de esquerda"

$\mathrm{O}$ cenário brasileiro encaixa-se em um contexto maior, e que envolve uma percepção de mudança de rumo político em diversos países da América Latina com a chegada ao poder de grupos percebidos como "de esquerda", fenômeno que se tornou conhecido como lefft turn (cf. CASTAÑEDA, 2006; CAMERON, 2009). No Brasil, a "virada à esquerda" levou ao poder, a partir de 2002, um conjunto de agentes que, historicamente, ocuparam um papel marginal no cenário político, e cuja relação com a mídia tradicional foi atravessada por relações que envolvem desconfianças recíprocas, mas também certo grau de dependência - já que boa parte do financiamento da imprensa é viabilizado pela verba gasta em publicidade pelo governo federal.

$\mathrm{O}$ apresentado nas linhas acima vai de encontro ao modelo informativo de jornalismo sobre o qual

\footnotetext{
A "blogosfera progressista" é formada pela atuação em rede de blogueiros jornalistas (alguns egressos da "grande mídia"), ativistas políticos ligados a partidos políticos de esquerda e meios de comunicação em formato tradicional concorrentes dos veículos da "grande imprensa".
} 
se assentam os pilares defendidos como norteadores da prática profissional no Brasil. Sob os moldes de perspectivas norte-americana ou mesmo centro-europeia (HALLIN; MANCINI, 2004; SIBERT, PETERSON; SCHRAMM, 1963), o jornalismo no Brasil seria caracterizado disfuncional. Acreditamos ser necessário romper com a lógica etnocêntrica tradicionalmente adotada para se compreender a complexidade do jornalismo brasileiro atual. Propomos, assim, um estudo comparativo que busque contemplar outras formas do fazer profissional adotadas para além do "mundo ocidental". Ao refletirmos acerca das relações entre imprensa e poder em diferentes países, pretendemos conferir contornos mais nítidos em torno da imprensa no Brasil enquanto "ecossissistema” complexo.

Para tanto, esta discussão articula-se em quatro eixos interrelacionados: 1) o desenvolvimento da imprensa e suas particularidades em cada país, abarcando modelos construídos sobre diferentes sistemas midiáticos (que tradicionalmente giram em torno do "modelo anglo-americano" de jornalismo); 2) a relação entre mídia, mercado, governo e partidos políticos; 3) a relação de jornais e jornalistas com a sociedade em que atuam; e 4) a relação histórica entre jornalismo e política no Brasil, contemplando o aparecimento de novos agentes possibilitados de entrar em cena com o desenvolvimento da Internet, em especial a rede dos "blogueiros progressistas". Por meio de uma perspectiva comparativa, o objetivo final é discutir e relacionar elementos que contribuam para compreender a cultura do jornalismo no Brasil hoje no que tange à comunicação política.

\section{Imprensa e modelos de jornalismo}

O modelo de jornalismo "imparcial", amplamente disseminado nas últimas décadas, relaciona-se aos Estados Unidos, e em grau menor à Inglaterra, podendo ser considerado uma "descoberta" do século XIX (CHALABY, 1996). Entretanto, pesquisas (SCHUDSON, 1978; NERONE; BARNHUST, 2003) indicam que, no mesmo período, havia circulação de periódicos partidários nos Estados Unidos e que o país encontrava-se em pleno processo de politização da mídia na primeira metade daquele século. As forças de mercado que guiavam a comercialização dos jornais são apontadas como impulsionadoras da politização da imprensa, de forma que disputa partidária e competição econômica caminhavam lado a lado, levando jornais concorrentes a valerem-se da afiliação partidária para adicionar valor ao seu produto.

Apenas no século seguinte, por volta de 1920, é que ganharia contornos mais nítidos o conceito tão caro aos jornalistas americanos - e que acabou por compor o repertório de legitimação também dos brasileiros: a objetividade, estratégia que teria como resultado a produção de relatos equilibrados. Conforme esse modelo, cada jornal é internamente plural, pois reproduziria em suas páginas diversos olhares sem que houvesse opinião do repórter ou da empresa jornalística em suas matérias.

Outros países destoam do modelo, caso da imprensa italiana, ao tradicionalmente manter a discussão política estritamente dentro dos limites dos partidos. Segundo a lógica mediterrânea, várias interpretações sobre um mesmo acontecimento seriam claramente apresentadas ao leitor, mas cada uma presente em um jornal distinto (pluralidade externa). Vinte anos após Speaking of the President (HALLIN; MANCINI, 1984), uma apresentação preliminar do problema em torno da relação entre jornalismo e política, os autores publicaram um esquema interpretativo de fôlego visando a compreender o jornalismo do "ocidente moderno". Lançado em 2004 (HALLIN; MANCINI, 2004), Comparing Media Systems pode ser compreendido como substituto à, até então, grande referência da área dos estudos comparativos em comunicação: o clássico Four Theories os the Press (SIBERT; PETERSON; SCHRAMM, 1963).

Entender o contexto de produção é relevante para compreender a lógica sobre a qual se assentam e os pontos de vista apresentados e defendidos pelos trabalhos. Four Theories deve ser lido tendo em mente os anos 60 como momento histórico e o país que adota como referencial, os Estados Unidos. Nesse período, ainda não havia formação de conglomerados midiáticos, mas a presença de empresas jornalísticas. O discurso liberal clássico confundia-se, afetando inclusive países da América Latina, como o Brasil - que vivia sob uma ditadura militar-, com uma "campanha" norte-americana pela liberdade de imprensa, ao defender o controle privado dos meios noticiosos, orientado pelo mercado ou lucro, com autonomia frente ao Estado e, portanto, capazes de exercer a atividade jornalística plenamente - cuja função essencial seria a prestação de serviços ao sistema político; "iluminar" ou "esclarecer" a audiência; e salvaguardar as liberdades individuais, inclusive em relação a desvios do governo quanto a seus propósitos originais (SIBERT; PETERSON; SCHRAMM, 1963).

$\mathrm{Na}$ verdade, em vez de quatro esquemas teóricos, como sugere o título, os autores apresentam apenas um modelo, ou o modelo: o libertário (relacionado aos EUA e à Grã-Bretanha) e a atualização deste, denominado "responsabilidade social", que dá conta da virada socialdemocrata inaugurada pela "Era Thatcher", sem abrir mão da lógica liberal. Os outros "modelos teóricos" contemplados no livro, a saber: "autoritário", 
no qual o Brasil se encaixaria em virtude da censura à imprensa, e "soviético comunista", são apresentados não como modelos, mas como "desvios" ou modalidades disfuncionais.

Com o pós a Guerra Fria, havia a expectativa de que o jornalismo americano seria amplamente adotado pelos mais diversos países, tornando-se algo "universal" (CHALABY, 1996). Essa lógica foi amplamente disseminada, promovendo uma ideia mais de homogeneidade que de alteridade. Os EUA, inclusive, atuaram valendo-se dos meios de comunicação (soft power) para difundir a ideia de "democracia sobre a tirania", de modo a promover reformas visando a garantir interesses comerciais em países da Europa Oriental e Ásia Central com a dissolução do regime soviético nos anos 80 (SUSSUMAN; KRADER, 2008).

Como veremos, a disseminação do modelo anglo-americano de fato ocorreu, porém adotou contornos bastante particulares em cada país em que foi introduzido. Enquanto o jornalismo anglo-saxão teria, em tese, se desenvolvido como campo autônomo ao da política e da literatura, o mesmo não pode ser dito com relação ao francês, por exemplo. Além disso, é problemática a alocação em uma mesma categoria países pertencentes a regiões heterogêneas, como América Latina, África e Ásia.

Assim pode ser percebido o trabalho de Hallin e Mancini (2004). De modo mais abrangente, Comparing Media Systems apresenta três modelos de sistemas midiáticos que sugerem explicar os traços predominantes em determinados países: 1) o Modelo Liberal configurase por um relativo predomínio dos mecanismos de mercado e dos meios de comunicação comerciais, com forte profissionalismo sem auto-regulamentação institucionalizada; 2) Democrático Corporativista, caracterizado por uma coexistência histórica dos meios de comunicação comerciais e os meios de comunicação ligados a grupos sociais e políticos organizados, e por um papel relativamente ativo, mas legalmente limitado do Estado; 3) o Pluralista Polarizado distingue-se pela integração dos meios de comunicação na política partidária, um desenvolvimento histórico mais fraco dos meios de comunicação comerciais e da cultura profissional no jornalismo, uma imprensa com baixa circulação e voltada para uma pequena elite, e um forte papel do Estado. Neste último estaria a América Latina. Mesmo advertidos de que se tratam de "tipos ideiais", ao se refletir acerca do lugar do Brasil nessa classificação percebe-se, mais uma vez, que o quadro é maior que a moldura na qual deveria se encaixar. Nesse sentido, a inclusão de novos atores estudados em perspectiva comparativa contribui para a melhor compreensão de como se articula a prática profissional em nosso próprio país.

\section{Pluralismo midiático}

Como podemos perceber, os esforços em desenhar modelos para a análise de sistemas midiáticos que contemplem diferentes culturas de jornalismo tendem a trabalhar sob a lógica de que aquilo que muito destoa do modelo liberal é concebido como algo ainda em fase de evolução ou, pior, disfuncional. E como pertinente a essa lógica, a presença de um Estado notadamente atuante (sobretudo politica e economicamente centralizador) é vista com desconfiança.

No tocante ao papel do governo federal, este teve, no Brasil, lugar importante ao subsidiar economicamente as organizações midiáticas. Porém, diferentemente do que ocorre em países como a Inglaterra, o Estado nunca teve atuação significativa como dono de organização midiática; tampouco há, como na Itália, o predomínio de jornais e outros meios de comunicação cujas linhas partidárias sejam realmente definidas. Pelo contrário, o sistema de transmissão brasileiro é quase inteiramente privado desde a sua concepção. Mas isso é suficiente para garantir a autonomia de um meio noticioso?

David Ryfe (2012) lembra que o período em que o jornalismo norte-americano desfrutou de maior autonomia em relação a outros campos, como os político e econômico, foi o compreendido entre os anos 1950 e 1970. Mesmo nessas décadas, porém, jamais atingiu completa autonomia, em virtude de permanecer fortemente atrelado às necessidades comerciais das organizações desde o nascimento do jornalismo comercial moderno. Assim, libertar-se do sistema partidário não significou completa independência, mas a necessidade de lidar com outros dilemas.

Em boa parte dos países asiáticos, o "mercado midiático" foi erguido em conformidade com o relacionamento que seus proprietários tinham com o Estado, que beneficiava aliados e suprimia aqueles que o contestavam. Não podemos dizer, portanto, que o processo de democratização na Ásia tirou de cena a figura do Estado dominante, apesar de enfraquecido (LEE, 2001). Tampouco devemos menosprezar o papel dos partidos políticos para a configuração da imprensa de alguns países e das negociações envolvidas entre agentes políticos para o desenvolvimento e a sobrevivência da atividade jornalística (MCCARGO, 2003).

O capitalismo de mercado, nesse contexto, fez florescer grandes empresas privadas que tiveram regimes autoritários como suporte, o que não significou a promoção de uma imprensa independente, seja em relação ao controle do Estado, ou mesmo (e talvez principalmente) dos ditames mercadológicos. Durante décadas, a luta anticomunista e a necessidade de modernização seriam utilizadas como justificativa para a repressão política e midiática em países como Coréia, Taiwan e Singapura. Isso porque a estabilidade 
política, promovida através da repressão (incluídos aí os golpes de Estado, como o que ocorreu em 1964 no Brasil), foi concebida como pré-requisito para o desenvolvimento econômico; mesmo que fosse necessária a supressão da liberdade de imprensa - o que aponta para as origens autoritárias da democracia liberal em certas partes do globo.

Além disso, o equilíbrio entre governo e partidos no jogo político deve ser considerado. Nesse sentido, tratar-se de um democracia presidencialista ou parlamentarista interfere no resultado da equação, uma vez que em sistemas onde os partidos possuem pouca relevância na dinâmica política, dois mediadores entre o campo do poder e o público em geral tendem a se destacar: o governo (e isso geralmente se explicita quando em democracias presidencialistas, uma vez que o governo tende a se personificar na figura do presidente) e os meios noticiosos (jornalistas e jornais de prestígio e/ou grande circulação). Além disso, a independência entre os três poderes existente no sistema presidencialista traz o jornalismo como protagonista no processo político, já que a imprensa se apresenta como responsável por viabilizar a comunicação entre o Executivo, o Legislativo, o Judiciário, e destes com o público. Daí viria a noção do jornalismo como Quarto Poder, como defendem os norte-americanos, para quem o jornal possui função de contraponto a serviço dos cidadãos para prevenir abusos do Estado, encargo cumulativo ao de mediador dos acontecimentos.

No Brasil, o amadurecimento de uma democracia presidencialista nos últimos trintas anos caminhou lado a lado ao fortalecimento de ao menos um partido político, o PT, que alcançou os mais altos índices de simpatia, votação e aprovação, no tocante à atuação à frente da presidência da República na última década. O que aponta para um modelo de democracia ${ }^{3}$ (cf. MANIN, 1995; ALBUQUERQUE, 2005) em que a variável "partidos

\footnotetext{
3 Neste trabalho, utilizamos como ponto de partida para refletir sobre o impacto ou não da variável "partidos políticos" na comunicação política em regimes democráticos os estudos de Manin (1995). São três tipos-ideais de governo representativo propostos pelo autor: 1) no "modelo parlamentar" o representante mantém uma relação direta com os eleitores, produzida por "[...] recursos prévios que atores políticos mobilizam na disputa pelo poder [...]. As eleições selecionam um tipo particular de elite: os notáveis [...]" (MANIN, 1995, p. 17); na 2) "democracia de partido", por outro lado, a política assume natureza de classe e os partidos políticos surgem exatamente para mobilizar esse novo eleitorado e o Parlamento torna-se reflexo das lutas sociais. A deliberação dos representantes ocorre nas discussões realizadas dentro dos partidos, o Parlamento deixa de ser um lugar onde posições iniciais podem ser alteradas por meio da troca argumentativa entre os sujeitos, uma vez que a posição da maioria já foi fixada previamente. Lá, as decisões políticas são tomadas após debates apenas como forma de lhes conferir validade; já 3) no modelo de "democracia de público", o foco desloca-se para a ênfase no papel dos meios de comunicação na política. Nesse processo, é enfatizada a individualidade dos políticos em detrimento das plataformas dos partidos. Os candidatos vitoriosos seriam, por conseguinte, não os de maior prestígio local, mas os com maior capacidade se dominar as técnicas da mídia, os "comunicadores".
}

políticos" ganha proporção na relação entre imprensa e política. Por outro lado, não se deve menosprezar o papel dos meios de comunicação quando o assunto é "fazer política". Um exemplo bastante estudado do uso de internet foi a campanha de Barack Obama (GOMES et al., 2009; RAINIE; SMITH, 2008, entre outros), que utilizou recursos de comunicação digital de forma pioneira de modo a atingir determinado nicho do eleitorado norteamericano: jovens adultos. E, apesar de Gomes et al. (2009, p. 24) tratar no referido texto prioritariamente do uso do Twitter, para quem “[...] o amplo acesso à informação política por meio de fontes diversificadas é um resultado positivo das campanhas virtuais, especialmente nas redes e mídias sociais, uma vez que esses espaços são propícios à exposição inadvertida [...]", nosso trabalho converge com do professor por acreditarmos que a "blogosfera progressista" também contribui garantir promover pluralidade de informações políticas, sobretudo por se posicionar como contraponto à "grande mídia". Como propõe a citação que abre este artigo, caberia à "grande mídia" desempenhar o papel de oposição, à medida que houve um esvaziamento desta iniciado com o governo de coalizão petista do presidente Lula, que ganhou forma mais robusta no mandato de Dilma Rousseff, também do PT, ficando a oposição restrita a quatro partidos: PSDB, DEM, PPS e PSOL ${ }^{4}$, cuja identificação com o eleitorado é menor. Sob esse aspecto, porém, uma parcela significativa dos meios noticiosos brasileiros seria menos uma "ala tucana", como sugere a charge que abre nossa discussão, apresentando uma complexidade bem maior que a mera função de ecoar a voz de um partido político espífico ou alinhamento automático a um candidato da direita política.

De modo geral, a noção de Quarto Poder, como foi apropriada na América-Latina, aponta para um modelo de distanciamento na relação entre imprensa e governo (WAISBORD, 2000); geralmente concebido e enfatizado como corrupto (HALLIN; PAPATHANASSOPOULOS, 2002). O mercado, por outro lado, seria o promotor da virtude, responsável por propiciar um jornalismo de qualidade (LAWSON, 2002). O papel do jornalista permanece relacionado à mediação, mas há certa missão civilizatória. Porém, a ideia de que o mercado promove virtude somente existe porque se entende que entre o mercado e os jornais há uma elite formada pelos jornalistas e que esta estaria a cargo de "educar" a população.

Algo semelhante ocorre em reação aos jornalistas da Grã-Bretanha, que também reivindicam a função

\footnotetext{
${ }^{4}$ Outros três, PSD, PTB e PR seriam considerados "independentes"; os demais compõem a base governista.
} 
de "instrutores ou educadores" (KÖCHER, 1986). $\mathrm{O}$ interessante é que o papel encontra-se relacionado a um aspecto do jornalismo de opinião e, portanto, surpreende vê-lo sendo requerido por profissionais do "modelo informativo". Em outro estudo (JAKUBOWICZ, 1992) também é possível identificar a função educadora da imprensa, mas desvinculada de uma experiência democrática: à época do apogeu do regime comunista, os jornalistas poloneses se encaravam, sobretudo, como educadores sociais. Diferentemente de seus colegas britânicos, porém, também ajudavam a ecoar a voz do partido comunista.

É pertinente observar a influência que o mercado exerceu, na Grã-Bretanha, para a propagação do discurso de distanciamento entre imprensa e partidos políticos, bem como para o estabelecimento de um jornalismo plural no que concerne à promoção da concorrência de opiniões distintas em um mesmo periódico. Apresentar-se como internamente plural se aproxima da forma como se posicionam alguns dos jornais de maior circulação e influência do Brasil, haja vista o que escreveu Susana Singer, Ombudsman da Folha de S. Paulo, na edição de 27 de outubro de 2013 (SINGER, 2013), ao afirmar que "o jornal não pode reproduzir a polarização estéril que reina na internet" $e$ que seus colunistas são pensados pela publicação não em termos de esquerda e direita, mas como reforço ao "pluralismo da Folha", de modo a tornar o jornal "a principal arena de debate político em 2014, ano de campanha eleitoral".

Por outro lado, o jornalismo se voltarmos nosso olhar para a Alemanha veremos uma forma distinta de atuação política, uma vez que as particularidades envolvidas em sua trajetória histórica, relacionadas à formação tardia como Estado-Nacional (apenas na segunda metade séc. XIX), proporcionaram o surgimento de uma diversificada imprensa regional, em que a maioria dos jornais era comprometida com um partido político. A visão que os jornalistas possuíam de si mesmos como pilares de um campo político acabava por substituir a necessidade de serem objetivos (KÖCHER, 1986). Isso teria contribuído para proporcionar maior coerência ou homogeneidade interna em relação à perspectiva defendida por diferentes órgãos. Soma-se a isso, o lugar em que se encontram os jornalistas na Alemanha, profissionais liberais que participam de todas as etapas do trabalho de elaboração da notícia, em vez da segmentação desse processo em tarefas, como ocorre na Grã-Bretanha e nos Estados Unidos, por exemplo. Ao possuir maior autonomia jornalística e liberdade editorial, o Redakteur alemão tende a expor mais suas próprias inclinações políticas em vez das da organização (ESSER, 1998), o que pode contribuir para proporcionar ao leitor uma identificação mais clara dos pontos de vista defendidos em um jornal, a começar pelo jornalista que é responsável pela notícia. Uma lógica que se distancia do ofício desenvolvido nas grandes redações no Brasil, mas, por outro lado, possui semelhanças no modo como trabalham os jornalistas brasileiros que migraram para o universo virtual e hoje atuam como blogueiros - em especial os autointitulados "progressistas".

\section{Culturas de jornalismo}

As experiências acima mencionadas nos levam a perceber que a forma como a imprensa se relaciona com outros agentes, assim como seu processo de construção em cada país, constituem fatores relevantes para o entendimento do lugar dos meios de comunicação noticiosos e dos próprios jornalistas em uma determinada cultura e como estes percebem seu papel e se apresentam à sociedade.

A noção de watchdog, por exemplo, só faz sentido, tal qual foi concebida, se a imprensa possui autonomia em relação ao Estado e baseia sua legitimidade nos cidadãos (WAISBORD, 2000). Ilustrativamente, apontamos a China como lugar em que houve a ressignificação do conceito pelos agentes políticos (DAN, 2010). Lá, os jornalistas se valem do conceito como elemento útil de legitimidade, porém a similaridade do que no país asiático recebeu a alcunha $Y u$ Lun Jian $D u$, na verdade, representa seu oposto, uma vez que é reconhecido e protegido pelo partido e está mais relacionado ao exercício do poder pelo governo que pelo público.

Sendo assim, é possível inferir que a forma como os jornalistas encaram e se posicionam em sua atividade é capaz de alterar as "características culturais" da imprensa. E isso acaba por influenciar no perfil do profissional que é atraído para a atividade jornalística: mais jovens e com menor grau educacional, por exemplo, na Grã-Bretanha em relação à Alemanha. No Brasil, curiosamente, o perfil dos profissionais que migraram para a internet e encontraram na blogosfera fonte de trabalho assemelha-se mais ao segundo país que ao primeiro: entre os jornalistas destacam-se aqueles com formação superior e maior experiência profissional conquistada ao longo de anos de trabalho na grande "mídia tradicional", É caso dos blogueiros-jornalistas Carlos Azenha (ex-Folha de S. Paulo, TV Globo, SBT, entre outros), além de Paulo Henrique Amorim (Veja, Exame, Rede Globo, CNN etc.), Rodrigo Vianna (Folha de S. Paulo, TV Globo etc.), entre outros.

Outro aspecto que merece ser contemplado diz das transformações sociais e a forma como estas afetarão a atividade jornalística enquanto negócio e atividade profissional. Uma recente publicação da revista The Economist (FOLDING PAPERS..., 2013) 
contribui para elucidar o fenômeno da migração de jornalistas para a blogosfera: trata-se de mercado de trabalho em franca expansão, voltado para um segmento específico da população brasileira que vem crescendo. $\mathrm{O}$ texto alerta para a agonia dos jornais, ao mesmo tempo em que a classe média dá boas vindas à mídia online. Na mesma matéria, o editor d' $O$ Estado de $S$. Paulo, Ricardo Gandour, expressava sua preocupação quanto à queda de qualidade no jornalismo, em virtude do aumento de meios noticiosos viabilizado pela internet. Vale lembrar que há alguns anos se discute no Brasil as estratégias encontradas pelos jornalistas e organizações noticiosas para defesa e manutenção de seu lugar de mediação. A principal seria apresentar a blogosfera como um território hostil, inseguro, onde é impossível confiar na informação a que se tem acesso (ALBUQUERQUE, 2007). Gandour não apenas confirma essa premissa, ao afirmar que a "extrema fragmentação das comunicações não pode ser saudável para a democracia", como também deixa a entender que o aumento de meios de informação talvez seja algo problemático. A questão é: ele refere-se à necessidade de "enxugamento" da quantidade de meios noticiosos ou de perspectivas políticas?

A ausência de pluralidade de pontos de vista políticos geralmente é relacionada a regimes autoritários. Entretanto, países que viveram experiências antidemocráticas possuem contribuições valiosas para se pensar a construção de uma imprensa e o lugar que esta reivindica na sociedade. Chamamos atenção para o caso de países como Rússia e Polônia, que aponta para a construção de uma cultura de jornalismo a partir de uma experiência particular, relacionado a um Estado cujas prioridades se opõem à lógica capitalista. Ainda à época da extinta União Soviética, quando havia lacunas entre os ideais socialistas e sua implementação, em que política e moral mostravam-se desemparelhadas, eram os jornalistas os convocados a "reparar" esses possíveis desvios. Eles se viam como um "braço" do governo, a face moral e humana do Estado. Ocupavam uma posição única como parte do partido-Estado (reproduzindo informação oficial), mas também eram inspirados a compor a intelligentsia responsável, inclusive, por fazer críticas ao governo (ROUDAKOVA, 2009), parte do projeto leninista de liderança que tinha a crítica/autocrítica como princípio.

Durante a perestroika, nos anos 80 , os jornalistas reivindicavam não apenas liderança moral, mas também politica. Dispunham de crédito com a sociedade e eram encorajados a buscar as causas das deficiências do socialismo, afirmando-se no direito de definir as prioridades e os objetivos políticos do país. Logo, as reformas iniciadas por Gorbachev elevaram a expectativa em torno do jornalismo, mas a economia
Russa entra em colapso na fase de transição para o capitalismo. A abertura do jornalismo russo ao mercado significou a queda do status dos jornalistas, uma vez que o jornal via-se atrelado a interesses comerciais, dependendo e submetendo-se a anunciantes, o que levou à construção do discurso de "jornalismo como prostituição" no país e ao colapso da confiança em meio à audiência.

A discussão ajuda a refletir acerca de como a relação entre imprensa, jornalistas, partidos políticos, mercado - e o peso que cada uma dessas variáveis exerce na equação - afeta a construção de um "lugar do jornalismo" na sociedade. No caso soviético, esse lugar era mais que o da mera intermediação proposta pelo modelo informativo, uma vez que à imprensa caberia atuar politicamente para assegurar o sucesso do projeto socialista. Podemos dizer, em certa medida, que os jornalistas-blogueiros brasileiros possuem pontos em comum com os jornalistas soviéticos. Sua construção se dá como grupo de elite, a partir do currículo ressaltado em suas páginas pessoais, mas não apenas por isso: essa proximidade se dá, sobretudo, por reivindicarem um lugar privilegiado e de prestígio em relação ao atual governo, remetendo a certa superioridade 5 . Mais que "imprensa alternativa", a "blogosfera progressista" se apresenta como aquela que faz as críticas ao PT e ao governo Dilma "pela esquerda". Nesse sentido, é interessante observar que a esquerda brasileira constitui um ecossistema complexo, formado desde por partidos mais "radicais" como por aqueles mais ao centro politicamente. Em meio a essa diversidade, o PT possui influência sobre a ala "progressista da blogosfera"; talvez não menos que o Partido Comunista do Brasil (PCdoB) $)^{6}$.

É possível identificar jornais e jornalistas atuando politicamente ao longo do globo. Em países asiáticos como a Tailândia, em que há alta fragmentação e estabilidade políticas, os jornais precisaram se adaptar e tornarem-se "polivalentes" para sobreviver em meio ao mercado e à "flutuabilidade" de governo. Ao adotarem uma "identidade camaleônica", buscam lidar com as múltiplas vozes que venham a ocupar a liderança do país, mantendo conexão com qualquer que seja a facção, partido ou grupo de interesse

\footnotetext{
5 Nesse aspecto, podemos dizer que essa não seria uma faceta apresentada apenas pelos jornalistas "de esquerda", mas algo parte da cultura jornalística brasileira de modo geral. Isso se daria em virtude de uma leitura particular que os profissionais brasileiro fizeram do conceito de Quarto Poder norte-americano e da noção de autoridade jornalística, em que mais que o papel de mediadores entre os três poderes, estes reivindicaram o papel de árbitros dos conflitos que possam ocorrer entre as instituições políticas, bem como intérpretes privilegiados do interesse nacional (ALBUQUERQUE, 2008).

${ }^{6}$ O jornalista Altamiro Borges, presidente do Centro de Estudos de Mídia Alternativa Barão de Itararé, sítio que reúne a "blogosfera progressista" é, inclusive, é militante do PCdoB.
} 
no poder (MCCARGO, 2003). Dessa maneira, os jornalistas tailandeses subvertem a lógica dicotômica de "pluralismo interno" (um jornal e múltiplas vozes, visando a promoção de perspectivas equilibradas que levariam, em última instância, à "imparcialidade") versus "pluralismo externo" (cada jornal defendendo uma perspectiva política), ao praticarem algo semelhante a um pluralismo externo, porém dentro de um mesmo jornal.

A experiência da Tailândia é universalizável em certos aspetos, pois contribui para a explicitação das relações que os jornalistas e meios noticiosos estabelecem para sobreviver e conquistar reconhecimento. Estar bem com grupos políticos em posição de poder diz menos sobre evitar censura, nos dias atuais, que em conquistar verba pública por meios comerciais, caso da disputa por maiores fatias no orçamento para a publicidade do Governo Federal no Brasil reivindicada pela "blogosfera progressista"

Por outro lado, nossa reflexão indica que só faz sentido um jornal posicionar-se em apoio a um determinado grupo político em particular quando há estabilidade política, com um sistema partidário organizado em torno de linhas ideológicas. E isso é válido tanto em democracias onde o Estado é mais atuante politica e economicamente, como naquelas em que sobressai a lógica liberal. Há estudos (STROUD, 2011) que propõem, inclusive, que as empresas jornalísticas norte-americanas estão em processo de retomada do partidarismo, expressando inclinações políticas para competir pela audiência. A seleção da notícia seria feita de modo a atingir um nicho específico de mercado idealmente identificável - o público formado por simpatizantes/militantes do Partido Republicano (a exemplo da emissora de TV Fox News) ou aqueles mais adeptos aos ideais propagados pelo Partido Democrata $(C N N)$.

A partir disso, podemos sugerir que há indícios de que algo semelhante também ocorra no Brasil dos dias atuais. $\mathrm{O}$ que pode ser considerado indício do amadurecimento da democracia de partidos brasileira, uma vez que esta seria um dos pilares capazes de sustentar a defesa de linhas ideológicas cada vez mais claras por jornais, revistas, emissoras de TV e componentes da blogosfera.

\section{Imprensa política no Brasil}

No Brasil, o envolvimento entre imprensa e política é marcado por transformações que não podem ser pensadas desvinculadas de seu contexto. A adaptação

\footnotetext{
Há uma demanda por parte do grupo de blogueiros para que o governo federal aumente a verba empregada em publicidade na internet em "mídias alternativas", questionando os $70 \%$ gastos pelo poder público com anúncios na "mídia tradicional".
}

do modelo anglo-americano de jornalismo, na década de 50, trouxe para as redações brasileiras as noções de profissionalismo defendidas por nossos vizinhos do norte, o que inclui a classificação da notícia como relatos isentos de opinião. Porém, se nos EUA os jornais se colocam como mediadores entre o governo $\mathrm{e}$ o público, e reivindicam para si o papel de promotores das informações de modo objetivo e imparcial, no Brasil houve uma "leitura muito particular da retórica americana do Quarto Poder". Os jornalistas brasileiros

[...] mais do que simplesmente servir como canal de comunicação entre os poderes (e destes com os cidadãos), reivindicaram o papel de árbitros dos conflitos que se estabeleceram entre as instituições políticas e de intérpretes privilegiados do interesse nacional. (ALBUQUERQUE, 2008, p. 11).

No país, "[...] até a década de 1940, a maioria dos diários era ainda essencialmente instrumento político." (RIBEIRO, 2003, p. 1). E foi apenas na década seguinte que o modo de se entender e se praticar o jornalismo no Brasil começou a mudar, motivado sobretudo por questões comerciais. Nas redações brasileiras, passou-se a privilegiar a informação, em detrimento da opinião, esta devendo se encontrar separada graficamente das notícias propriamente ditas. Assim, consideramos os anos 50 como marco para o desenvolvimento do jornalismo praticado atualmente no país, uma adaptação ou naturalização (ALBUQUERQUE, 2008) de um modelo importado dos Estados Unidos que tem nos conceitos de notícia, de factual, imparcialidade e objetividade elementos centrais.

Ana Paula Goulart Ribeiro (2003) identifica uma dimensão interessante da evolução do ofício em solo nacional, que demonstra que o jornalismo daqui não pode ser entendido como simplesmente cópia fiel ao modelo anglo-americano ou a qualquer outro. Se a partir da década de $50 \mathrm{o}$ aspecto econômico começou a prevalecer nas empresas jornalísticas em detrimento das determinações políticas, tal qual como nos Estados Unidos do século XIX, o aspecto político não desapareceu totalmente das redações brasileiras, já que

[...] o apoio a determinados grupos que estavam no poder ou na oposição (dependendo da conjuntura) era essencial para garantir a sobrevivência de algumas empresas, fosse através de créditos, empréstimos, incentivos ou mesmo publicidade. (RIBEIRO, 2003, p. 10).

Além disso, o aspecto político não era apenas conjuntural, mas intrínseco às redações, como destaca Albuquerque

[...] o papel importante que os jornalistas comunistas desempenharam no processo de modernização 
do jornalismo brasileiro, entre as décadas de 1950 e 1970, mesmo em jornais conservadores. (ALBUQUERQUE, 2008, p. 7),

bem como a participação do governo militar para a determinação da obrigatoriedade do diploma para o exercício profissional do jornalismo, estabelecida por meio do decreto-lei 972, de 1969.

Produto da junta militar que governou o Brasil durante dois meses naquele ano, e formulado nos termo do Ato Institucional $\mathrm{n}^{\circ} 5$, o decreto provavelmente tinha como objetivo diminuir a influência dos comunistas nos jornais, incentivando a formação de profissionais mais técnicos e menos políticos. (ALBUQUERQUE, 2008, p. 7).

Ao contrário do que pretendiam os militares, a atividade política permaneceu presente nas redações brasileiras. O engajamento da mídia na atividade política, inclusive, é apresentado por Albuquerque (2008, 2012) como variável necessária para a análise da relação entre mídia e política no Brasil, ao lado da força dos partidos políticos. Para além da relação com os partidos, sobretudo do que se refere aos "jornalistas comunistas" (ALBUQUERQUE; SILVA, 2007), podemos dizer que a maioria dos meios de comunicação brasileiros foi condescendente ou mesmo atuou ativamente como porta-voz para os governos militares (LIMA; RAMOS, 1988; SMITH, 1997; DIAS, 2012). Quando o regime caiu, a grande mídia rapidamente transferiu a sua lealdade ao regime democrático recém-nascido (GUIMARÃES; AMARAL, 1988) e as novas circunstâncias lhes proporcionaram um conjunto inteiramente novo de oportunidades políticas, pricipalmente no que diz de reivindicar para si o direito de realizar um papel político central na nova era democrática. Caberia, portanto, à nossa imprensa arbitrar os conflitos existentes entre executivo, legislativo e judiciário, de modo prestar um serviço público, garantindo o bom funcionamento de todo o sistema, agindo, enfim, em nome do interesse nacional (ALBUQUERQUE, 2005). E "nome da opinião pública", ao longo desse período, a "grande mídia" ajudou a eleger presidentes, mobilizar a opinião pública a apoiar as políticas do governo, e agiu para mitigar crises políticas e financeiras (MIGUEL; SIMÕES, 2000; PORTO 2012).

No entando, os anos 2000 apresentariam novas perpectivas no cenário midiático.

[...] Enquanto a grande mídia resistiu a um ambiente midiático competitivo, os blogs alteraram essa situação ao introduzirem uma arena largamente disponível de discursos políticos baseada em uma concepção alternativa a partir da imprensa tradicional.
(CARLSON, 2007, p. 269; tradução nossa) ${ }^{8}$. No terreno da comunicação, novas tecnologias e meios tradicionais possuem papéis ainda em fase de construção ou reestruturação, porém o estado é de coexistência.

Seria pouco razoavel imaginar que a esfera civil pudesse prescindir, na sua tentativa de aumentar a sua capacidade de influenciar a decisao politica, do emprego dos meios de comunicacão de massa - que, ainda, controlam a esfera de visibilidade publica da política -, supondo que a internet sozinha teria a capacidade de devolver-lhe as oportunidades de participacão política de que necessita. Tanto a internet quanto os meios tradicionais de massa devem ser explorados, isso sim, no sentido de que se dobrem ao interesse publico. Como isso pode ser feito, entretanto, ja e uma outra hist6ria. (GOMES, 2008, p. 325-326).

Com aparecimentos e a proliferação de blogueiros disputando o terreno da informação com a imprensa tradicional, vivenciamos um movimento de adaptação e reafirmação da autoridade jornalística, sobretudo pela grande imprensa (ALBUQUERQUE, 2007; ALDÉ; CHAGAS, 2007; CARLSON, 2007). No caso brasileiro em particular, nos "novos tempos" começa a ganhar força um movimento de migração de jornalistas em direção à blogosfera de modo a atuarem como "imprensa independente", alguns profissionais de renome, como Luis Nassif (2006), que se autointitula o introdutor do jornalismo eletrônico no país. O fenômeno de proliferação de blogs ganhou combustível com a crise política de 2005, quando

[...] blogs de política, especialmente os de jornalistas já conhecidos, tornaram-se lugar de discussões e tomada de posição pública. Trata-se de uma apropriação bastante original do formato, associado comumente a um diário. (ALDÉ; CHAGAS, 2007, p. 29).

A presença, hoje, de uma "blogosfera progressista", constituída por agentes que abertamente manifestam apoio ao atual governo, apresentando-se como críticos à esquerda do governo do PT, enriquece e torna plural o ambiente midiático brasileiro. Mais ainda, ao questionar e buscar demolir a aura de credibilidade que (auto) construída em torno dos grandes meios noticiosos, produzem consteúdo político com viés político distinto do majoritariamente adotado pela "grande mídia". No terreno circunscrito do jornalismo/comunicação de massa, o que se estabele é uma disputa pela manutenção de autoridade jornalística (por parte da "grande mídia") ou conquista desta (pela "blogosfera progressista").

\footnotetext{
Do original: "While news outlets have long endured a competitive media environment, blogs alter this situation by introducing a widely available arena of political discourse based on an alternative conception from traditional news media."
} 
Porém, para a comunicação politica, o que se apresenta é um rico terreno de estudo, ainda pouco explorado, sobretudo se olharmos para a "blogosfera progressista" enquanto ecossistema midiático, como conjunto em detrimento de blogs ou blogueiros isolados.

\section{Considerações finais}

Os estudos comparativos, ao nos ajudarem a mapear e explicar as similaridade e diferenças entre aspectos do jornalismo em diferentes países, contribuem para situarmos e empreendermos uma melhor discussão sobre nossa própria imprensa e os profissionais que a compõem. A relação que se estabelece com outras culturas propõe a convergência do Brasil com nossos vizinhos latino-americanos quando consideramos mudanças sociais e políticas; assim como a presença de governos situados à esquerda, com uma política voltada para o diálogo com países considerados "suspeitos" pelo eixo liberal.

A leitura particular da vocação liberal da imprensa, que se define como "Quarto Poder", aproxima nossos jornalistas dos profissionais que atuam em localidades tão distantes geográfica e culturalmente de nós como os centro-asiáticos. Porém, não devemos cometer o equívoco que criticamos, ao olhar para as semelhanças como se estas significassem homogeneidade. No caso do Brasil, por exemplo, diferentemente do que ocorre na China, a apropriação do discurso liberal se dá, por uma significativa parcela dos meios noticiosos, objetivando a oposição ao atual governo. Enquanto que a outra parcela de nossa imprensa caberia a ocupação de um "entre-lugar", uma vez que tende a apoiar o governo petista, mas não seria corretamente nomeada alternativa ou governista, ao valer-se do posicionamento "à esquerda" para também pressionar a Presidência da República na reivindicação de maiores fatias do investimento em publicidade pela Administração Pública.

Dessa maneira, acreditamos que um olhar "periférico", lapidado com base em uma perspectiva comparativa, seria mais construtivo para o estudo das culturas de jornalismo. Menos por aquilo que destoa ou configurar-se-ia inicialmente como desvio a um "modelo" e mais a partir de um lugar de reinterpretação. Apesar de os anos 50 terem sido considerados um marco na história da imprensa nacional, com o jornalismo político-literário perdendo espaço para uma forma de produção da notícia que privilegiasse a informação, incorporando, portanto, os ideais de objetividade e imparcialidade, é notória a permanência do envolvimento da imprensa brasileira com a política e os partidos políticos. A ascenção do Partidos dos Trabalhadores ao poder nos últimos treze anos, somada a mudanças no terreno da comunicacão de massa, sobretudo com o desenvolvimento da internet, possibilitaram a entrada em cena de um conjunto de atores que atuam por meio de blogs, disputando terreno com a "grande mídia" e se apresentando como apoiadores dos governos petistas. O fenômeno "blogosfera progressista" contribui para lançar luz, entre outros aspectos, sobre a comunicação política na atualidade, evidenciando uma "tomada de partido" no jornalismo brasileiro. Mas, como a perspectva comparativa nos deixa ver, o viés partidário, se não é novidade no Brasil, sequer deve ser considerado um ponto de desvio no ideal de "bom jornalismo".

\section{Referências}

ALBUQUERQUE, A. A mídia como "poder moderador": uma perspectiva comparada. In: ENCONTRO NACIONAL DA COMPÓS, 17., 2008, São Paulo. Anais... Associação Nacional dos Programas de Pós-Graduação em Comunicação, 2008. Disponível em: <http://www.compos.org.br/data/biblioteca_305. pdf $>$. Acesso em: 15 nov. 2015.

ALBUQUERQUE, A. On models and margins: comparative media models viewed from a brazilian perspective. In: HALLIN, D.; MANCINI, P. (Ed.). Comparing media systems beyond the western world. New York: Cambridge University Press, 2012. p.75-95.

ALBUQUERQUE, A. Take a walk on the wild side: os blogs como outro do jornalismo. In: PEREIRA, V. A. (Org.). Cultura digital trash: linguagens, comportamentos, entretenimento e consumo. Rio de Janeiro: E-Papers, 2007. p. 61-76.

ALBUQUERQUE, A.; SILVA, M. A. R. Preparados, leais e disciplinados: os jornalistas comunistas e a adaptação do modelo de jornalismo americano no Brasil. E-Compós, v. 9, p. 1-30, 2007.

ALBUQUERQUE, A. Política partidária e política midiática: substituição ou coexistência? Contemporanea (Bologna, Italy), v. 1, n. 3, p. 9-37, 2005.

ALDÉ, A.; CHAGAS, V. A febre dos blogs de política. Famecos, v. 33, p. 29-40, 2007.

BRAGA, M. S. S.; PIMENTEL JUNIOR, J. Os partidos políticos realmente não importam? Opinião Publica, v. 17, n. 2, 2011

CAMERON, M. Latin America's left turns: beyond good and bad. Third World Quarterly, v. 2, n. 30, p. 331-348, 2009. http://dx.doi.org/10.1080/01436590802681082.

CARLSON, M. Blogs and journalistic authority: the role of blogs in US Election Day in 2004. Journalism Studies, v. 8, n. 2, p. 264-279, 2007.

CASTAÑEDA, J. Latin America's left turn. Foreign Affairs, v. 3, n. 85, p. 28-43, 2006. http://dx.doi. org/10.2307/20031965.

CHALABY, J. Journalism as an Anglo-American invention: a comparison of the development of French and AngloAmerican journalism, 1830s-1920s. European Journal of Communication, v. 11, n. 3, p. 303-326, 1996. 
DAN, H. Power and right: "Yu Lun Jian Du" as a practice of Chinese media from an institutionalism perspective. Journalism Studies, v. 12, n. 1, p. 106-118, 2010.

DIAS, A. B. O presente da memória: usos do passado e as (re)construções de identidade da Folha de S. Paulo, entre o 'golpe de 1964'e a 'ditabranda'. 2012. 203 p. Dissertação (Mestrado em Comunicação, Setor de Ciências Humanas, Letras e Artes)-Universidade Federal do Paraná, Curitiba, 2012.

ESSER, F. Editorial structures and work principles in British and German newsrooms. European Journal of Communication, v. 13, n. 3, p. 375-405, 1998. http:// dx.doi.org/10.1177/0267323198013003004.

FOLDING PAPERS: as the middle class embraces online media, newspapers are struggling. The Economist, Rio de Janeiro, 13 jul. 2013. Disponível em: <http://www. economist.com/news/americas/21581741-middle-classembraces-online-media-newspapers-are-strugglingfolding-papers $>$. Acesso em: 15 nov. 2015

GOMES, W. et al. Politics 2.0: a campanha on-line de Barack Obama em 2008. Revista de Sociologia e Politica, v. 34, n. 17, p. 29-43, 2009.

GOMES, W. Internet e participação política. In: GOMES, W.; MAIA, R. Comunição e democracia: problemas \& perspectiva. São Paulo: Paulus, 2008. p. 293-326.

GUIMARÃES, C.; AMARAL, R. Brazilian television: a rapid conversion to the new order. In: ELISABETH, F. (Ed.). Media and politics in Latin America: the struggle for democracy. London \& Newbury Park: Sage, 1988. p. 15-137.

HALLIN, D.; MANCINI, P. Comparing media systems: three models of media and politics. Cambridge: Cambridge University Press, 2004.

HALLIN, D.; MANCINI, P. Speaking of the president: political structure and representational form in US and Italian television news. Theory and Society, v. 13, n. 6, p. $829-850,1984$. http://dx.doi.org/10.1007/ BF00209215.

HALLIN, H.; PAPATHANASSOPOULOS, S. Political clientelism and the media: southern Europe and Latin America in comparative perspective. Media, Culture \& Society, v. 24, n. 2, p. 175-195, 2002.

JAKUBOWICZ, K. From party propaganda to corporate speech? Polish journalism in search of a new identity. Journal of Communication, v. 42, n. 3, p. 64-73, 1992. http://dx.doi.org/10.1111/j.1460-2466.1992.tb00798.x.

KÖCHER, R. Bloodhounds or missionaries: role definitions of German and British journalists. European Journal of Communication. v. 1, n. 1, p. 43-64, 1986. http:// dx.doi.org/10.1177/0267323186001001004.

LAWSON, J. Building the fourth estate: democratization and the rise of a free press in Mexico. Berkeley: University of California Press, 2002.

LEE, C. Beyond orientalist discourses: media and democracy in Asia. The public, v. 8, n. 2, p. 7-20, 2001.

LIMA, V. A.; RAMOS, M. C. A televisão no Brasil: desinformação e democracia. In: FLEISCHER, D. (Ed.). Da distensão à abertura: as Eleições de 1982. Brasília: Editora da UnB, 1988. p. 215-233.
MANIN, B. As metamorfoses do governo representativo. Revista Brasileira de Ciências Sociais, v. 10, n. 29, p. 5-33, 1995.

MCCARGO, D. Media and politics in Pacific Asia. New York: RoutledgeCurzon, 2003.

MIGUEL, L. F.; SIMOES, P. The Globo television network and the election of 1998. Latin American Perspectives, v. 27, n. 6, p. 65-84, 2000. http://dx.doi. org/10.1177/0094582X0002700605.

NASSIF, L. Quem é Luis Nassif? 2006. Disponível em: $<$ http://luisnassifonline.blog.uol.com.br/>. Acesso em: 15 nov. 2015

NERONE, J.; BARNHURST, K. US newspaper types, the newsroom, and the division of labor, 1750-2000. Journalism Studies, v. 4, n. 4, p. 435-449, 2003. http:// dx.doi.org/10.1080/1461670032000136541.

PAIVA, D.; TAROUCO, G. S. Voto e identificação partidária: os partidos brasileiros e a preferência dos eleitores. Opinião Pública, v. 17, n. 2, p. 426-451, 2011

PORTO, M. P. Media power and democratization in Brazil: tv Globo and the dilemmas of political accountability. New York: Routledge, 2012.

RAINIE, L.; SMITH, A. The internet and the 2008 election. Pew Internet \& American Life Project, 2008. Disponível em: $<$ http://www.pewinternet. $\operatorname{org} / 2008 / 06 / 15 /$ the-internet-and-the-2008-election/>. Acesso em: 12 fev. 2015.

RIBEIRO, A. P. G. Jornalismo, literatura e política: a modernização da imprensa carioca nos anos 1950. Estudos Históricos, v. 31, p. 147-160, 2003.

RIBEIRO, E.; CARREIRÃO, Y.; BORBA, J. Sentimentos partidários e atitudes políticas entre os brasileiros. Opinião Publica, v. 17, n. 2, p. 333-368, 2011

ROUDAKOVA, N. Journalism as "prostitution": understanding Russia's reaction to Anna Politkovskayas's murder. Political Communication, v. 26, n. 4, p. 1-34, 2009. http://dx.doi.org/10.1080/10584600903053890.

RYFE, D. Can journalism survive? An inside look at American newsrooms. Malden: Polity Press, 2012.

SCHUDSON, M. Discovering the news: a social history of American newspapers. New York: Basic Books, 1978.

SIBERT, F.; PETERSON, T.; SCHRAMM, W. Four theories of the press: the authoritarian, libertarian, social responsibility and soviet communist concepts of what the press should be and do. Chicago: University of Illinois Press, 1963.

SINGER, S. Arena de debates: ao trazer novos colunistas, o jornal não pode reproduzir a polarização estéril que reina na internet. Folha de S. Paulo, São Paulo, Ombudsman, 27 out. 2013. Disponível em: $<$ http:// www1.folha.uol.com.br/fsp/ombudsman/135919arena-de-debates.shtml>. Acesso em: 15 nov. 2015

SMITH, A.-M. A forced agreement: press acquiescence to censorship in Brazil. Pittsburgh: University of Pittsburgh Press, 1997.

STROUD, N. J. Niche news: the politico of news choice. New York: Oxford University Press, 2011. 
SUSSUMAN, G.; KRADER, S. Template revolutions: marketing U.S. regime change in Eastern Europe. Westminster Papers in Communication and Culture, v. 5, n. 3, p. 91-112, 2008.

VEIGA, L. F. O Partidarismo no Brasil: 2002/2010. Opinião Pública, v. 17, n. 2, p. 400-425, 2011
WAISBORD, S. Watchdog journalism in South America: news, accountability, and democracy. New York: Columbia University Press, 2000.

Recebido: 02 maio, 2015 Aceito: 15 ago., 2015 